\title{
KIRSCHNER WIRES VERSUS HERBERT SCREW FIXATION WITH BONE GRAFT IN CASE OF NONUNITED SCAPHOID WAIST FRACTURE
}

\author{
By \\ Ammar Ahmed, Ahmed Badawy and Galal Hegazy \\ Department of Orthopedic Surgery, Faculty of Medicine, Al-Azhar University \\ Corresponding Author: Ammar Ahmed, \\ E-mail: ammar_ahmed993@gmail.com
}

\begin{abstract}
Background: Scaphoid nonunion is challenging to manage because of the geometry of the scaphoid, the direction and type of fracture, and the vascular pattern of the blood supply to the scaphoid. Fracture proximal to the perforating vessels on the dorso-radial surface of the scaphoid can cause significant bone ischemia of the proximal pole.

Objective: To compare the impact of the Kirschner wires versus Herbert screw fixation with iliac bone graft on the rate of union, time to union, correction of deformity, and clinical outcome in adults with nonunited scaphoid waist fracture without avascular necrosis.

Patients and Methods: We prospectively randomized 40 patients to undergo corticocancellous iliac bone grafting and internal fixation either with multiple Kirschner wires or Herbert screw. This study was conducted in the Department of Orthopedic surgery at Al-Hussien University Hospital, Faculty of Medicine, Al-Azhar University during the period from February 2018 to April 2020. Radiographs, clinical outcome measures (pain, range of motion, and grip strength) were done pre- and post-operatively.

Results: No significant difference detected between the two groups with respect to the time to union, rate of union, deformity correction, pain analysis, range of motion, grip strength, and complications.

Conclusion: Combination of impaction of iliac bone graft, and internal fixation with k-wire or Herbert's screw provided a good option for treatment of scaphoid nonunion. However, because of kirschner wires has a shorter operative time, lower cost and easy application as compared with the Herbert screw, so $\mathrm{k}$ wire may be a good alternative to Herbert screw.
\end{abstract}

Keywords: Scaphoid, Nonunion, Scaphoid nonunion, DISI, Herbert screw, Kirschner wire, Scaphoid waist fracture

\section{INTRODUCTION}

The scaphoid is the most commonly fractured carpal bone and account for $60 \%$ of all carpal fractures (Kawamura and Chung, 2010). Approximately about $10 \%$ of displaced scaphoid fractures fail to unite despite appropriate immobilization (Patrick, 2010).
The natural history of the untreated scaphoid waist fracture nonunion often involves apex dorsal angulation with bone loss and collapse (hump- back or flexion) deformity (Hernández-Ramajo et al., 2014).

The conventional treatment of scaphoid waist fracture nonunion with humpback deformity typically involves 
the use of bone graft and internal fixation. The goal of surgery is first adequately to reduce the scaphoid, thereby restoring the carpal height and alignment. Fernandez (2010) described a method of fixation using a volar wedge bone graft secured with Kirschner wires. However, Herbert and Fisher (2010) described the use of Herbert screw fixation.

The aim of the present study was to compare the impact of the Kirschner wires versus Herbert screw fixation with iliac bone graft on the rate of union, time to union, correction of deformity, and clinical outcome in adults with nonunited scaphoid waist fracture without avascular necrosis.

\section{MATERIALS AND METHODS}

This study was conducted at the Department of Orthopedic Surgery in AlHussien University Hospital, Faculty of Medicine, Al-Azhar University during the period from February 2018 to April 2020. IRB approval was obtained from the ethical committees of the Faculty of Medicine, Al-Azhar University. At the time of the enrolment, a written informed consent was obtained from the participants with consideration to declaration of Helsinki. The inclusion criteria were patients between the ages of 18 and 60 years with non-united scaphoid waist fractures that had not healed six months after the initial injury.

The exclusion criteria were bilateral scaphoid fractures, history of open fractures, trans-scaphoid perilunate or lunate dislocations, associated fractures in the hand or upper extremities, previous surgical treatment, stage II or higher scaphoid nonunion advanced collapse
(SNAC), and scaphoid non-unions with avascular necrosis (AVN). Seventy-five patients with scaphoid waist fracture nonunion were evaluated to participate in the study.

Diagnosis of the scaphoid waist fracture non-unions was based on the posteroanterior and lateral radiographs of the wrist, CT scan of the wrist along the longitudinal axis of the scaphoid, and MRI of the wrist to exclude AVN. Patients who did not meet the entry criteria were 28 patients (seven patients were less than 16 years old, five presented less than six months after the initial injury, five had trans-scaphoid perilunate dislocation, four had proximal pole nonunion with AVN, four had stage II SNAC, and three had stage III SNAC wrist). Forty four patients with scaphoid waist fracture nonunion were divided into 2 equal groups: Group received Kirschner wires fixation (K-wire group), and group received Herbert screw fixation (Herbert group). Two patients discontinued the intervention and two were lost to follow up after four weeks. Finally, 40 patients (K-wire group $[\mathrm{n}=20]$ and Herbert group [n $=20$ ) were analyzed. The standard posteroanterior and lateral radiographic views evaluated both pre-and postoperative scapholunate angle, radiolunate angle and the lateral intrascaphoid angle was measured pre- and post- operatively on the sagittal CT scan of the wrist along the longitudinal axis of the scaphoid (De Carli et al., 2017).

\section{Statistical analysis:}

Data were collected, revised, coded and entered to the Statistical Package for the Social Science (IBM SPSS) version 20. The quantitative data were presented 
as mean, standard deviations and ranges. Also qualitative variables were presented as number and percentages. Chi-square test was done for comparison between groups regarding qualitative data. Independent t-test was done for comparison between two independent groups with quantitative data and parametric distribution. The confidence interval was set to $95 \%$ and the margin of error accepted was set to $5 \%$. So, the pvalue $<0.05$ was considered significant. Radio lunate angle was tested using Mann-Whitney U test.

\section{Surgical technique:}

With supine position and supinated forearm Surgery was performed under general anesthesia with upper arm tourniquet control inflated only to $150 \mathrm{~mm}$ $\mathrm{Hg}$ above systolic blood pressure. FCR tendon and tuberosity of the scaphoid was palpated and the scaphoid approached through a 4-cm longitudinal volar incision centered over the tuberosity of the scaphoid lateral to the flexor carpi radials (FCR) tendon. The bed of the FCR was incised in line with the skin incision, and the radioscaphocapitate ligament was incised longitudinally to expose the

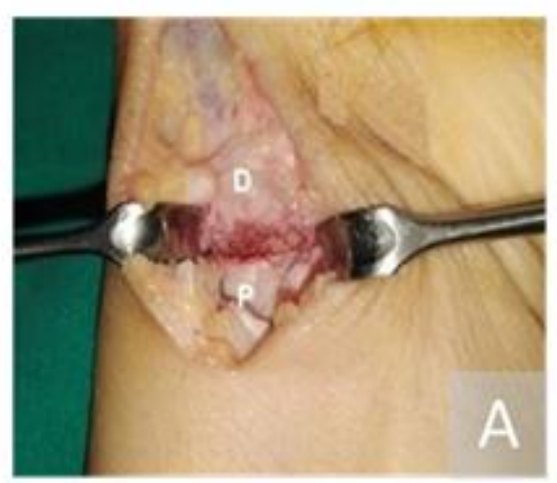

fracture. The scaphoid was inspected, and the fibrous tissue and sclerotic bone resected up to the normal looking bone. Curettage of each scaphoid pole was essential to expose the healthy bleeding cancellous bone and prepare an adequate cavity to accept the graft (Fig.1). The scaphoid reduced, and its length restored by introducing a lamina spreader in the gap. Acorticocancellous wedge graft was harvested from the ipsilateral iliac crest and packed into the prepared cavity. Satisfactory scaphoid and lunate alignment confirmed by a $\mathrm{C}$-arm image intensifier. In patients randomized for $\mathrm{K}$ wires fixation, the scaphoid was fixed with 0.045-in K-wires under image intensify guidance in a retrograde manner with convergent K-wire placement (Figure 1).

In patients randomized for Herbert screw fixation, the scaphoid was fixed with Herbert bone screw $3 \mathrm{~mm}$ in a retrograde manner. The final screw position was checked and confirmed with the use of an image intensifier. Finally, the capsule and radioscaphocapitate ligament were repaired and the skin was sutured.

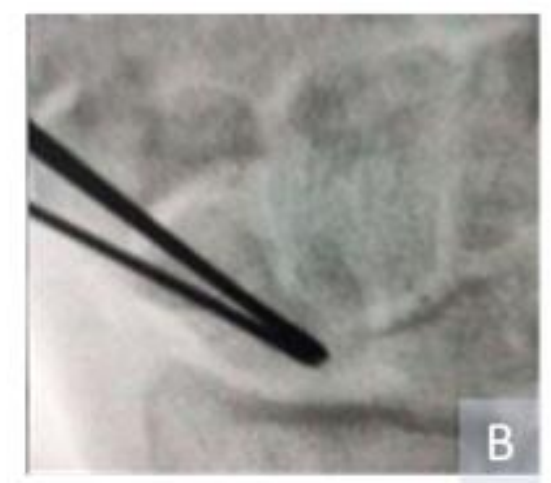

Figure (1): Generous curettage of each scaphoid pole to prepare an adequate cavity to accept the graft. P proximal pole and D distal pole. A, Fluoroscopic PA view of the wrist shows the K-wires inserted in a convergent direction. B. 
AMMAR AHMED et al.,

\section{Follow up:}

Postoperative X-rays were examined for fracture reduction and $\mathrm{K}$-wire as well as Herbert screw position. Four radiographic views of the wrist (standard $\mathrm{PA}$, lateral, $45^{\circ}$ pronation oblique, and PA with ulnar deviation) were obtained at two week intervals to detect union or complications such as arthritis, nonunion or carpal malalignment. The skin sutures were removed two weeks after surgery, and a short arm thumb spica cast had to be worn for an additional six weeks and then a short arm removable splint until the radiographic union. In the $\mathrm{K}$-wire group, the wires were removed after radiographic union. Patients commenced hand physiotherapy sessions under the supervision of aspecialized hand physiotherapist with gentile hand and wrist exercises followed by aggressive wrist exercises, and heavy activities were allowed after scaphoid union. Gradual return to an office job was allowed within the confines of the cast but manual work was allowed after scaphoid union and within the limits of pain. Full return to work and recreational activities were allowed after union and pain relief. The time of immobilization of both groups, the date of bony union, the rate of union and the complications were recorded. Serial clinical examination till time of union and at the last follow up for evaluation of the functional outcome using Mayo modified wrist score (Megerle et al., 2012). 


\section{RESULTS}

No differences were found between the $\mathrm{K}$-wire group and Herbert group with respect to age, sex, hand dominance, side of injury, mechanism of injury, occupation, fracture classification (Table 1).

Table (1): Data distribution

\begin{tabular}{|c|c|c|c|c|c|}
\hline \multirow{2}{*}{ Parameters } & \multicolumn{2}{|c|}{$\begin{array}{c}\text { Herbert screw } \\
\text { Group } \\
\text { (No.=20) }\end{array}$} & \multicolumn{2}{|c|}{$\begin{array}{c}\text { K-wire wires } \\
\text { Group } \\
(\text { No.=20) }\end{array}$} & \multirow[t]{2}{*}{$P$ value } \\
\hline & Mean & SD & Mean & SD & \\
\hline Age & 26.35 & 3.558 & 30.40 & 6.676 & \multirow{2}{*}{0.022} \\
\hline Range & \multicolumn{2}{|c|}{$25-27$} & \multicolumn{2}{|c|}{$29-33$} & \\
\hline $\begin{array}{l}\text { Gender } \\
\mathrm{M} / \mathrm{F}\end{array}$ & \multicolumn{2}{|c|}{$15 / 5$} & \multicolumn{2}{|c|}{$17 / 3$} & $>0.05$ \\
\hline \multicolumn{5}{|l|}{ Habits } & \multirow{2}{*}{$>0.05$} \\
\hline Smoking/No smoking & \multicolumn{2}{|c|}{$10 / 10$} & \multicolumn{2}{|c|}{$14 / 6$} & \\
\hline \multicolumn{5}{|l|}{ Side } & \multirow{3}{*}{$>0.05$} \\
\hline $\mathrm{Rt}$ & \multirow{2}{*}{\multicolumn{2}{|c|}{$\frac{14 / 20}{6 / 20}$}} & \multicolumn{2}{|c|}{$12 / 20$} & \\
\hline \multirow[t]{2}{*}{$\mathrm{Lt}$} & & & \multicolumn{2}{|c|}{$8 / 20$} & \\
\hline & $\mathbf{N}$ & $\%$ & $\mathbf{N}$ & $\%$ & \multirow{4}{*}{$>0.05$} \\
\hline \multicolumn{5}{|l|}{ Non-union type } & \\
\hline Type D2 & 14 & $70 \%$ & 16 & $80 \%$ & \\
\hline Type D3 & 6 & $30 \%$ & 4 & $20 \%$ & \\
\hline \multicolumn{5}{|l|}{ Mode of trauma } & \multirow{4}{*}{$>0.05$} \\
\hline FOOSH & 15 & $75 \%$ & 12 & $60 \%$ & \\
\hline Athletic activity & 5 & $25 \%$ & 6 & $30 \%$ & \\
\hline motorcycle accident & 0 & $0 \%$ & 2 & $10 \%$ & \\
\hline \multicolumn{5}{|l|}{ Occupation } & \multirow{4}{*}{$>0.05$} \\
\hline Skilled & 12 & $60 \%$ & 11 & $55 \%$ & \\
\hline Heavy manual & 3 & $15 \%$ & 2 & $10 \%$ & \\
\hline Light manual & 5 & $25 \%$ & 7 & $35 \%$ & \\
\hline \multicolumn{5}{|l|}{ Previous treatment } & \multirow{3}{*}{$>0.05$} \\
\hline Plaster of Paris & 15 & $75 \%$ & 17 & $85 \%$ & \\
\hline Physiotherapy & 5 & $25 \%$ & 3 & $15 \%$ & \\
\hline
\end{tabular}

Both groups were similar in terms of pre-operative clinical and radiographic parameters. No statistically significant differences were found between the two groups regarding the post-operative clinical and radiographic outcomes. There was significant improvement in the clinical and radiographic outcome measures pre- to post-operative for both groups (Tables 2, 3). 
AMMAR AHMED et al.,

Table (2): The results of preoperative and postoperative outcome according to Mayo score

\begin{tabular}{|l|c|c|c|c|c|c|}
\hline \multicolumn{2}{|c|}{ Groups } & \multicolumn{2}{|c|}{$\begin{array}{c}\text { Herbert screw } \\
\text { Group }\end{array}$} & \multicolumn{2}{c|}{$\begin{array}{c}\text { Kirschner wires } \\
\text { Group }\end{array}$} & \multirow{2}{*}{ P value } \\
\cline { 3 - 6 } Score & & $\mathbf{N}$ & $\mathbf{\%}$ & $\mathbf{N}$ & $\%$ & \\
\hline \multirow{3}{*}{ Preoperative } & Fair & 7 & $35 \%$ & 8 & $40 \%$ & \\
\cline { 3 - 6 } & Bad & 13 & $65 \%$ & 12 & $60 \%$ & \multirow{3}{*}{$>0.05$} \\
\hline \multirow{3}{*}{ Postoperative } & Excellent & 9 & $45 \%$ & 13 & $65 \%$ & \\
\cline { 2 - 6 } & Good & 7 & $35 \%$ & 4 & $20 \%$ & \\
\cline { 2 - 6 } & Fair & 2 & $10 \%$ & 2 & $10 \%$ & \\
\cline { 2 - 6 } & Poor & 2 & $10 \%$ & 1 & $5 \%$ & \\
\hline
\end{tabular}

Table (3): Comparisons between Preoperative and postoperative radiographic

\begin{tabular}{|l|c|c|c|c|c|c|c|}
\hline \multirow{7}{*}{ Groups } & \multicolumn{3}{|c|}{ Preoperative } & \multicolumn{3}{c|}{ Postoperative } & \multirow{2}{*}{ P value } \\
\cline { 2 - 7 } & Mean & SD & Range & Mean & SD & Range & \\
\hline Herbert & $80^{\circ}$ & 5.426 & $66^{\circ}-87^{\circ}$ & $52^{\circ}$ & 7.412 & $41^{\circ}-59^{\circ}$ & $<0.001$ \\
\hline Scapholunate angle & $29^{\circ}$ & 7.883 & $22^{\circ}-28^{\circ}$ & $10^{\circ}$ & 1.680 & $8^{\circ}-14^{\circ}$ & $<0.001$ \\
\hline Radiolunate angle & 0.441 & 0.024 & $0.48-0.58$ & 0.482 & 0.0163 & $0.46-0.53$ & $<0.001$ \\
\hline Carpal hight index & $67^{\circ}$ & 4.864 & $60^{\circ}-74^{\circ}$ & $36^{\circ}$ & 5.832 & $34^{\circ}-47^{\circ}$ & $<0.001$ \\
\hline Lateral intrascaphoid angle & $80^{\circ}$ & 4.732 & $66^{\circ}-87^{\circ}$ & $51^{\circ}$ & 5.231 & $42^{\circ}-60^{\circ}$ & $<0.001$ \\
\hline K-wire & $28^{\circ}$ & 3.423 & $22^{\circ}-30^{\circ}$ & $13^{\circ}$ & 2.626 & $8^{\circ}-16^{\circ}$ & $<0.003$ \\
\hline Scapholunate angle & 0.441 & 0.021 & $0.48-0.58$ & 0.482 & 0.022 & $0.46-0.53$ & $<0.041$ \\
\hline Radiolunate angle & $67^{\circ}$ & 5.432 & $58^{\circ}-75^{\circ}$ & $37^{\circ}$ & 6.413 & $32^{\circ}-48^{\circ}$ & $<0.001$ \\
\hline Carpal height index
\end{tabular}

\section{DISCUSSION}

Combination of impaction of iliac bone graft, and internal fixation with K-wire or Herbert's screw provides a good option for treatment of scaphoid nonunion to achieve bony union, restore scaphoid anatomy, improve wrist function, and prevent arthritis. The common sites of bone graft harvesting for scaphoid nonunion are the distal radius and iliac crest. Iliac crest graft permits greater retrieval of marrow and more osteogenic cells (Jarrett et al., 2011). Therefore, iliac crest graft can provide superior osteogenic properties compared with distal radius bone graft. Although several studies (Kirkham \& Millar, 2012 and Park et al., 2013) reported earlier union rate in some instance of unstable scaphoid nonunion with the use of cancellous iliac bone graft. Our preference was to use corticocancellous graft, as this may be more appropriate in the setting of large intercalary defects causing significant carpal collapse. There are three fixation methods used in the treatment of scaphoid fracture nonunion (Kirschner wires, screw, plate) but there is no study in the current literature directly compares these methods. The Herbert screw was significantly stronger in resisting bending forces as compared to paired parallel Kirschner wires but is unable to withstand cyclical multi axis loading or rotation (Luria et al., 2010). Our follow-up protocol was to continue immobilization until radiographic union achieved. A meta-analysis reported that bone graft 
with screw fixation achieved $94 \%$ union, and wedge graft with Kirschner wires achieved $77 \%$ union with the average time to union as 20 weeks (Merrell et al., 2012).

In our study, the rate of union in case of kirshner wires was $90 \%$ versus Herbert screw was $80 \%$ and the mean time to union was14 and 15 weeks respectively. The explanation of this result might relate to the use of Kirschner wires in a convergent direction to fix the scaphoid. This allowed the K-wires to pass through more surface area of the scaphoid and allowed for a more targeted placement into the proximal pole, thus increasing the fracture reduction stability and accelerating the union. Meisel et al. (2017) used the same fixation technique and reported $100 \%$ union rate with cancellous iliac bone grafting in the treatment of scaphoid nonunion. Moreover, our reported result regarding the union rate was consistent with Reigstad et al. (2010), and found that in the K-wire analysis, there was a higher union rate as compared to the groups fixed with screws. The K-wire group had a higher estimated incidence of union than the screw group (91\% versus $88 \%$, respectively), a difference that persisted when used with vascularized grafts (Kwire $94 \%$ versus screw $87 \%$ ).

\section{CONCLUSION}

There were no differences in the impact of one method on the time to union, rate of union, deformity correction, and the clinical outcomes. Herbert screw fixation was technically more demanding in terms of technique than K-wires, and the incidence of technical errors may play an eminent role in the occurrence of nonunion. However, because of easy application of Kirschner wires, and low cost, especially in developing countries, it may be a good alternative to Herbert screw. The limitation of the study includes its single center nature that limits its external validity.

\section{REFERENCES}

1. De Carli P, Donndorff AG, Torres MT, Boretto JG and Gallucci GL. (2017): Combined Tenodesis-Capsulodesis for Scapholunate Instability: Minimum 2-Year Follow-Up. J Wrist Surg., 6(1): 11-21.

2. Fernandez DL (2010): A technique for anterior wedge-shaped grafts for scaphoid nonunions with carpal instability. J Hand Surg Am., 9: 733-737.

3. Herbert TJ and Fisher WE (2010): Management of the fractured scaphoid using a new bone screw. J Bone Joint Surg Br., 66:114-123.

4. Hernández-Ramajo R, Martin-Ferrero MA, Simón-Pérez C and Muñoz-Moreno MF. (2014): Results of surgical treatment of carpal scaphoid pseudoarthrosis using the FiskFernández technique. Revista Española de Cirugía Ortopédica y Traumatología (English Edition), 58(4): 229-236.

5. Jarrett P, Kinzel V and Stoffel K (2011): A biomechanical comparison of scaphoid fixation with bone grafting using iliac bone or distal radius bone. J Hand Surg Am., 32:1367-1373.

6. Kawamura $\mathrm{K}$ and Chung $\mathrm{KC}$ (2010): Treatment of scaphoid fractures and nonunions. J Hand Surg Am., 33:988-997.

7. Kirkham SG and Millar MJ (2012): Cancellous bone graft and Kirschner wire fixation as a treatment for cavitary-type scaphoid nonunions exhibiting DISI. Hand, 7:86-93.

8. Luria S, Hoch S, Liebergall M, Mosheiff $\mathbf{R}$ and Peleg E (2010): Optimal fixation of acute scaphoid fractures: finite element analysis. J Hand Surg., 35:1246-1250. 
9. Megerle $\mathbf{K}$, Keutgen $\mathbf{X}$, Mueller $\mathbf{M}$, Germann $G$ and Sauerbier M. (2012): Treatment of scaphoid non-unions of the proximal third with conventional bone grafting and mini-Herbert screws: an analysis of clinical and radiological results. Journal of Hand Surgery (European Volume), 33(2): 179-185.

10. Meisel E, Seal A, Yao CA, Ghiassi A and Stevanovic M (2017): Management of scaphoid nonunion with iliac crest bone graft and K-wire fixation. Eur J Orthop Surg Traumatol., 27:23-31.

11. Merrell GA, Wolfe SW and Slade JF (2012): Treatment of scaphoid nonunions: quantitative meta-analysis of the literature. J Hand Surg Am., 27:685-691.
12. Park H, Yoon J, Jeon I, Chung $H$ and Kim J (2013): A comparison of the rates of union after cancellous iliac crest bone graft and Kirschner-wire fixation in the treatment of stable and unstable scaphoid nonunion. Bone Joint J., 95:809-814.

13. Patrick CN. (2010): Diagnosis and treatment of scaphoid fractures. Radiologic Technology, 82(2): 161-178.

14. Reigstad O, Thorkildsen R, Grimsgaard C, Reigstad A and Rokkum M (2010): Healing of ununited scaphoid fractures by Kirschner wires and autologous structural bone grafts. Scand J Plast Reconstr Surg Hand Surg., $44: 106-111$. 
مقارنة بين تثبيت كسر وسط العظمة الزورقية غير الملتئم بو اسطة أسلاك معدنية أو مسمار هربرت ورقعة وقة عظمية عمار أحمد، أحمد بدوي، جلال حجازي قسم جراحة العظام، كلية الطب، جامعة الأزهر

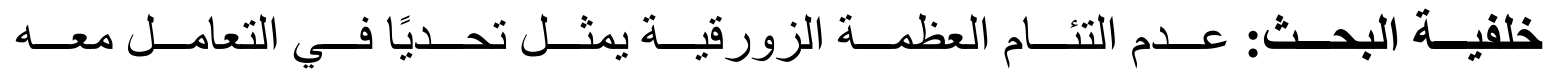

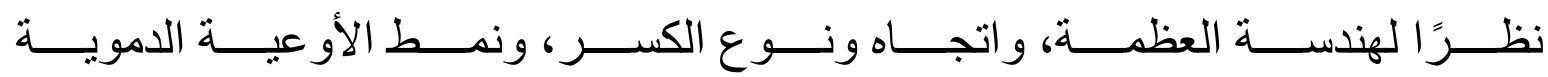

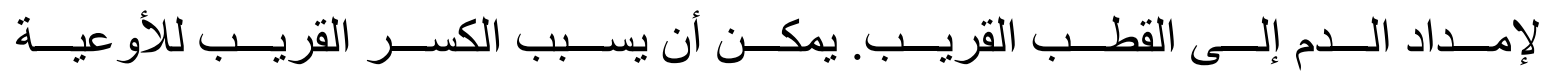

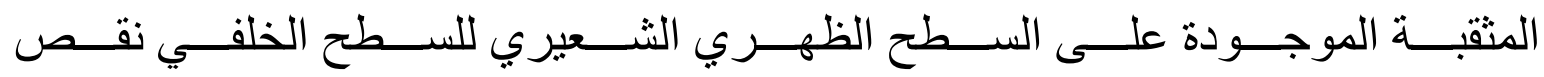

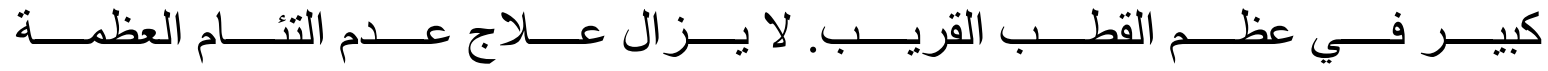

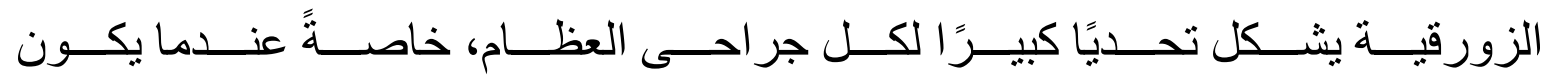
مرتبطًا بضعف الأو عية الدموية للقطب القريب.

الهـــف مــن البحــث: مقارنـــة إبـــتخدام مســـمار هيربــرت مقابــل اســلاك كيرشنر في علاج عدم التئام وسط العظمة الزورقية.

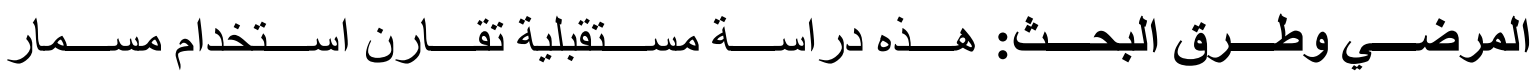

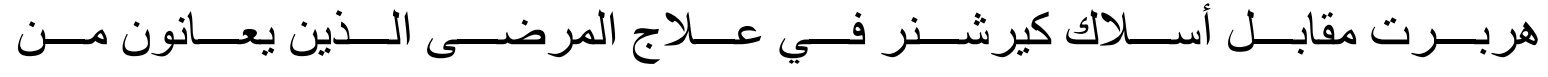

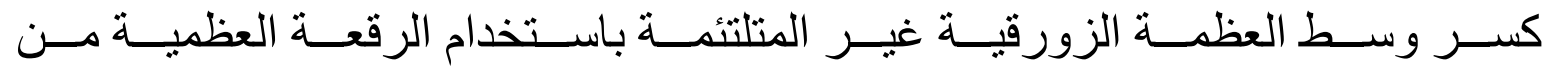

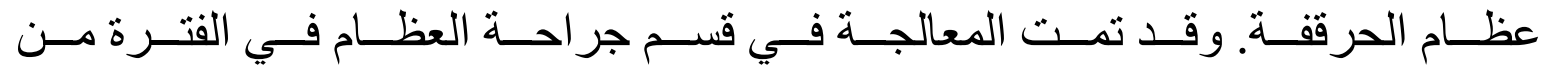
فبر اير 2018 حتى ابريل 2020 في مستثفى الحسين الجامعى.

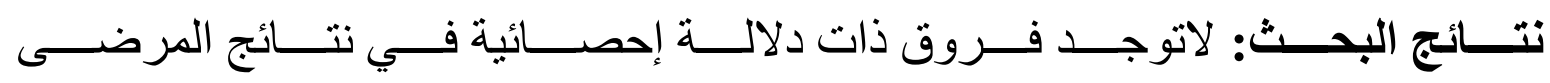

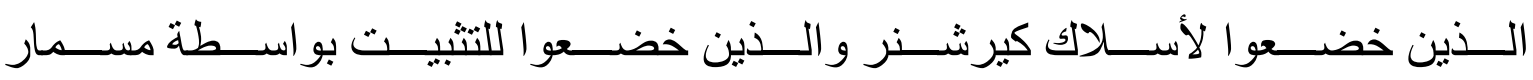

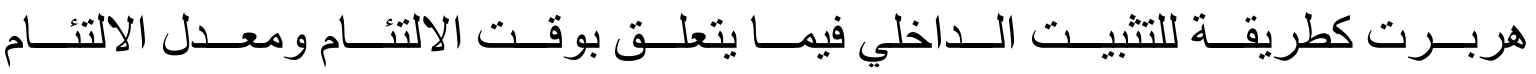

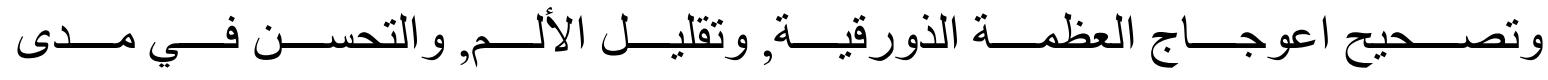

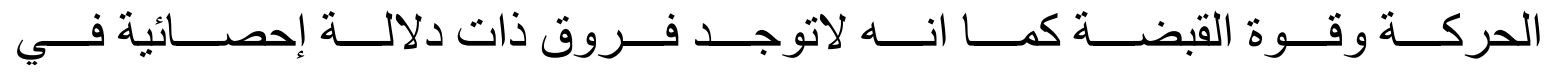




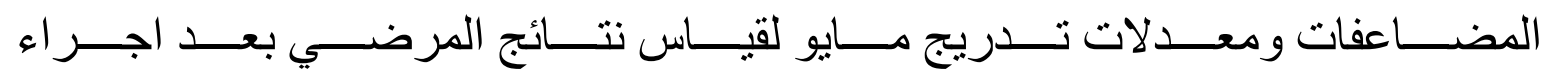

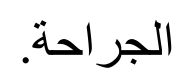

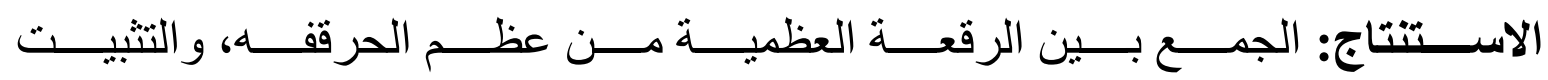

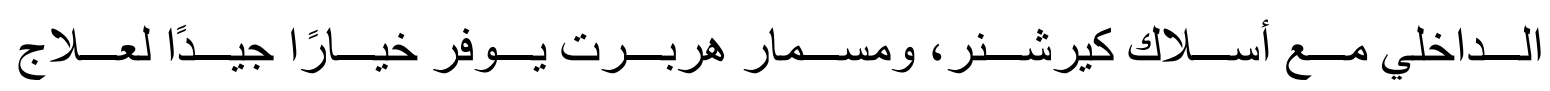

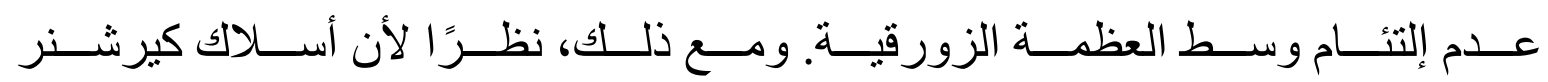

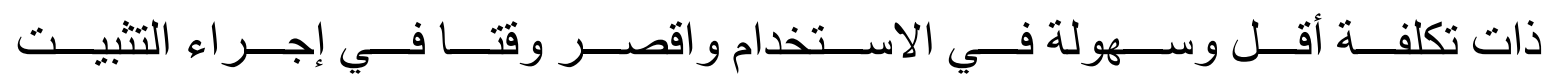

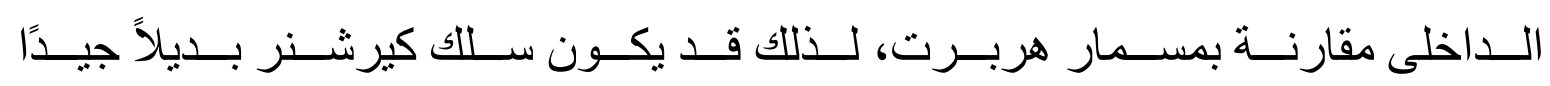
لمسمار هربرت.

الكلمــات الدالـــة: ســـافويد، عـــدم التئــام العظمـــة الزورقيــة، مســمار هربــرت، سلك كيرشنر، كسر وسط العظمة الزورقية. 